\title{
Incidence, characteristics and outcomes of patients with severe community acquired- MRSA pneumonia
}

\author{
K.Z. Vardakas*,\#, D.K. Matthaiou*,\# and M.E. Falagas*,
}

ABSTRACT: We evaluated the published data for the incidence, characteristics and outcomes of patients with community-acquired pneumonia (CAP) due to methicillin-resistant Staphylococcus aureus (MRSA). The estimated incidence of MRSA CAP is $0.51-0.64$ cases per 100,000.

We identified 74 articles reporting data on 114 patients. Influenza like symptoms was reported in $41 \%$ of patients. Pneumonia improved in 59 (54.1\%) out of 109 patients; 49 (44.5\%) out of 110 patients died. The duration of hospitalisation was $38.1 \pm 24.9$ and $8.3 \pm 11.7$ days, respectively. The duration of intensive care unit (ICU) stay was $18.9 \pm 13.6$ and $6.8 \pm 9.7$ days, respectively. 76 strains carried the Panton-Valentine leukocidin gene.

The univariate analysis showed that multi-organ failure $(p<0.001)$, leukopenia $(p<0.001)$, admission to ICU $(p<0.001)$, mechanical ventilation $(p<0.001)$, use of aminoglycosides after culture results $(p<0.001)$, shock $(p=0.001)$, acute respiratory distress syndrome $(p=0.001)$, influenza like symptoms $(p=0.008)$, disseminated intravascular coagulation $(p=0.042)$ and rash $(p=0.04)$ were the factors associated with death.

\section{KEYWORDS: Pneumonia, resistance, Staphylococcus aureus}

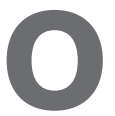
ne of the common causes of infection of all organs of the human body is Staphylococcus aureus. It is armed with a variety of virulence factors that facilitate adherence of and invasion to host tissues in addition to structures that disable host defenses and toxins that induce septic syndromes [1]. Furthermore, S. aureus has acquired genes that promote resistance for several classes of antibiotics; the most important to date is the mecA gene that confers resistance to methicillin and almost all $\beta$-lactams [2]. From the clinical point of view, methicillin-resistant $S$. aureus (MRSA) has become the primary pathogen of skin and soft tissue infections, but invasive infections also occur [2-4]. Among them, nosocomial pneumonia (NP), healthcare-associated pneumonia (HCAP) and community-acquired pneumonia (CAP) are of major importance due to the morbidity and mortality attributed to them [5-7].

The strains associated with NP/HCAP and CAP have distinct characteristics. The former contains the staphylococcal cassette chromosome SCCmec types I-III, while the latter contains SCCmec types IV and V. In addition, community-acquired (CA)-MRSA strains are susceptible to more classes of antibiotics [8,9]. Finally, toxins like
Panton-Valentine leukocidin (PVL) have been identified more frequently in CA-MRSA strains.

Although the incidence of MRSA NP/HCAP has been evaluated in several studies [10], the incidence of MRSA CAP is unknown $[8,9,11]$. S. aureus is responsible for $1-10 \%$ of CAP cases reported in the literature [12-14]. Studies describing patients with $S$. aureus CAP included only a very small number of MRSA cases [15-17]. Therefore, we sought to study systematically the available evidence in order to identify the incidence, characteristics and outcomes of patients with MRSA CAP.

\section{METHODS}

\section{Literature search}

A systematic search of PubMed and Scopus was performed by two independent reviewers. A combination of the terms "S. aureus", "staphylococcal", "methicillin-resistant", "communityacquired pneumonia", " pneumonia", "necrotizing pneumonia", "sepsis" and "toxic shock syndrome" were used. We also searched reference lists of retrieved articles and review papers for relevant studies. A time limit was set to only include articles written after 1985, when the first reports of CAMRSA infections were reported (January 1985 to September 2008).

\section{AFFILIATIONS}

*Alfa Institute of Biomedical Sciences (AIBS), Athens, "Dept of Medicine, "G. Gennimatas" General Hospital, Thessaloniki, Greece, and

"Dept of Medicine, Tufts University School of Medicine, Boston, MA, USA.

\section{CORRESPONDENCE}

M.E. Falagas

Alfa Institute of Biomedical Sciences (AIBS)

9 Neapoleos Street

15123 Marousi

Greece

E-mail:m.falagas@aibs.gr

Received:

March 122009

Accepted after revision:

June 052009

First published online:

June 182009 


\section{Study selection and data extraction}

All articles reporting data on patients with MRSA CAP could be included (population based studies, case reports, case series, cohorts, case-control studies, cross-sectional, randomised controlled trials). A language restriction was set for articles published in English, French, German, Italian, Spanish, Greek and Scandinavian. Inclusion was stratified according to available data on S. aureus susceptibility; in the absence of such data, studies were excluded from the analysis. Studies were also excluded from the review if clinical, microbiological and outcome data regarding individual patients or groups of patients with MRSA pneumonia were not available. Studies evaluating animal models were not eligible for inclusion.

Subsequently, data on demographics, history, risk factors for CA-MRSA (close contact with CA-MRSA colonisation or infection [18], prison incarceration [19, 20], contact sports [21, $22]$, recent military service [23], males having sex with males [24], intravenous drug use [25-27], steam bath use [28, 29], recent antibiotic use before the current infection [8]), severity and course of the disease, antibiotic use or need for intensive care unit (ICU) treatment and/or outcome of the infection were extracted from the studies. Hospitalisation was not an inclusion criterion. Both primary and secondary cases of CAP (haematogenous spread from other sites of infection) could be included.

\section{Definitions}

MRSA CAP was defined according to the definition of the Center for Disease Control and Prevention (CDC). A case of CA-MRSA was defined as illness compatible with CAP, in which MRSA was cultured from sputum or blood in an outpatient setting or $<48 \mathrm{~h}$ after hospital admission, and with none of the following healthcare risk factors: recent hospitalisation; surgery; dialysis, or residence in a long-term care facility $<1 \mathrm{yr}$ before the onset of illness; and permanent indwelling catheter or percutaneous medical device [30]. In addition, the definition was broadened to include cases in which the genotyping data (pulsed-field gel electrophoresis (PFGE), multilocus sequence typing or other techniques) provided evidence of a community strain.

CAP was defined as a baseline chest radiograph demonstrating new or progressive infiltrates, consolidation with or without effusion, and four of the following signs and symptoms: cough; new or worsened purulent sputum production; rales and/or signs of pulmonary consolidation; dyspnoea and/or hypoxemia; fever $\left(\geqslant 38^{\circ} \mathrm{C}\right)$; respiratory rate $\geqslant 20$ breaths $\cdot \mathrm{min}^{-1}$; systolic hypotension $(<90 \mathrm{mmHg})$; heart rate $\geqslant 120$ beats $\cdot \mathrm{min}^{-1}$; altered mental status; requirement for mechanical ventilation; white blood cell (WBC) count $\geqslant 10,000$ cells $\cdot \mathrm{mm}^{-3}$ with $\geqslant 15 \%$ immature neutrophils; or leukopenia (WBC count $\leqslant 4,500$ cells $\cdot \mathrm{mm}^{-3}$ ). The severity of CAP was based either on the opinion of the author of each article or the need for ICU treatment. A patient received appropriate initial antibiotic therapy if the isolate recovered from blood or sputum was susceptible to at least one of the antibiotics included in the empirical regimen.

\section{Statistical analysis}

The extracted data was converted to variables and analysed accordingly. Data was analysed with SPSS 15.0 software (SPPS Inc, Chicago, IL, USA). For categorical variables, the Chisquared test or Fisher's exact was used. For continuous variables, an independent sample t-test was used. For all tests performed, a two-tailed p-value $<0.05$ was considered as denoting statistical significance.

\section{RESULTS}

\section{Selected studies}

Figure 1 shows the process of screening and selection of studies included in the systematic review. The initial search revealed a total of 2,602 studies. Of which, 1,292 were published from 1985 and onwards. After screening according to the inclusion criteria,

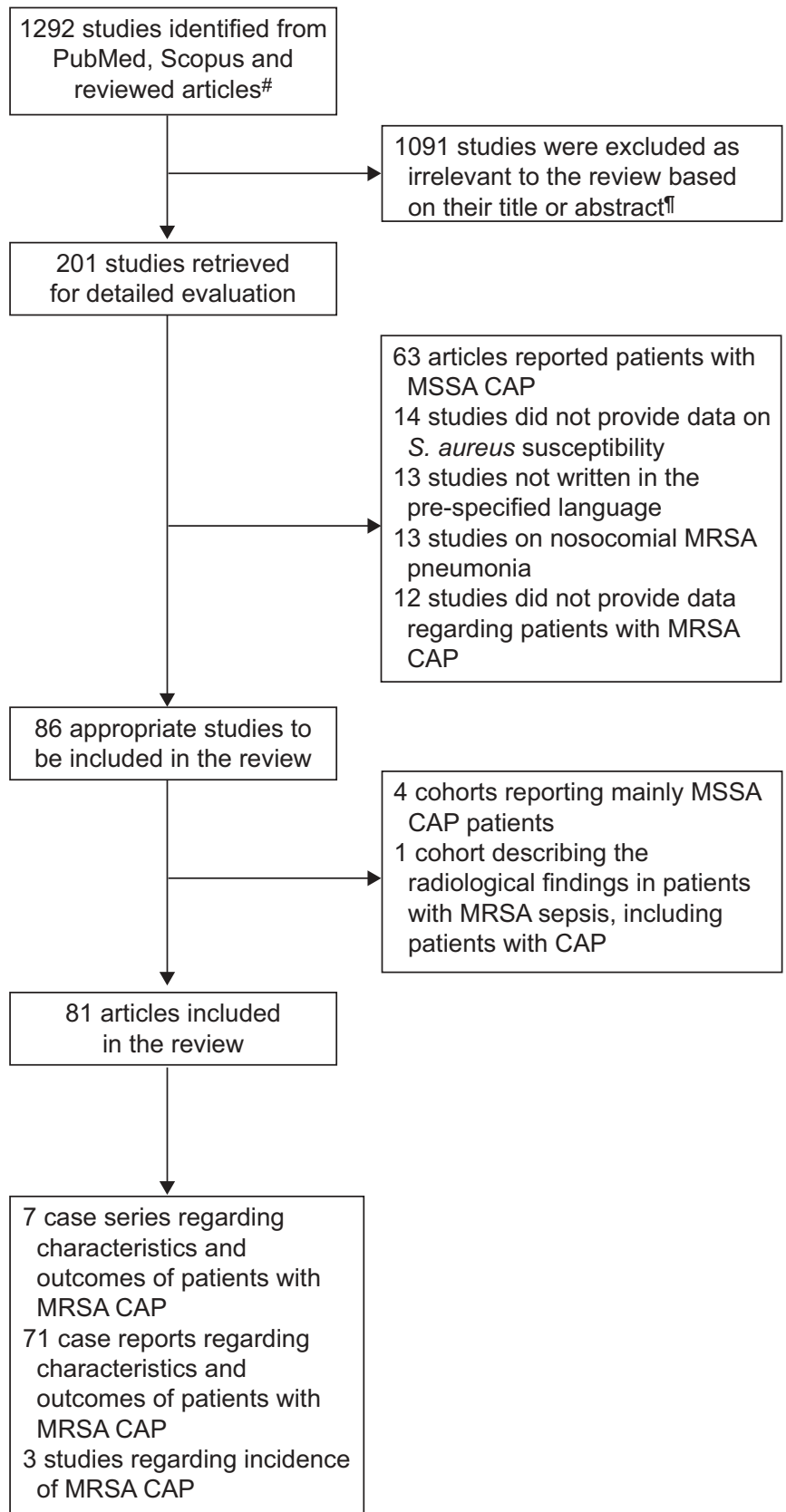

FIGURE 1. Flow diagram of the reviewed studies. MSSA: methicillin-sensitive Staphylococcus aureus (S. aureus); CAP: community-acquired pneumonia; MRSA methicillin-resistant $S$. aureus. \#: the majority of studies were found in both databases; ": include studies on nosocomial pneumonia, effectiveness of antimicrobial agents for CAP, cohorts of CAP patients without data regarding MRSA CAP, community acquired-MRSA infections other than CAP. 
201 articles were retrieved for detailed evaluation. 115 were excluded for reasons shown in figure 1 . Thus 81 studies were included in the systematic review [31-111]. Three of these reports provided data regarding the incidence of MRSA infections [31-33]. The remaining studies provided data regarding the characteristics and outcomes of patients with MRSA CAP (71 case reports and 7 case series) [34-111].

\section{Incidence of MRSA CAP}

We could not identify any study that sought to investigate the incidence of MRSA CAP. Two reviews reported that the evidence on epidemiology and characteristics of MRSA CAP is unknown and is extrapolated from studies on patients hospitalised with MSSA (methicillin-sensitive S. aureus) CAP (which is also scarce) [112,113]. One of them also commented that "this should be attributed to the lack of routine culture in patients with uncomplicated pneumonia" [113]. Several studies reported that after the implementation of the antipneumococcal vaccine the incidence of Streptococcus pneumoniae CAP decreased with a simultaneous increase in MRSA CAP, especially in cases complicated with pleural effusions [114-116]. Accordingly, an increase in staphylococcal infections, caused primarily by an increase in MRSA infections, has been confirmed [117, 118].

However, we came across studies that reported the incidence of CA-MRSA infections and also included patients with MRSA CAP. FRIDKIN et al. [31] reported that the annual incidence of CA-MRSA infections (based on population-based surveillance in Baltimore (MD, USA) and Atlanta (GA, USA), and hospitallaboratory sentinel surveillance of 12 hospitals in Minnesota (USA) between 2001 and 2002) was 25.7 cases per 100,000 in Atlanta and 18.0 per 100,000 in Baltimore. In both areas, the incidence was higher among patients $<2$ yrs of age than in patients $>2$ yrs of age. In Atlanta the incidence was also higher among Blacks than Whites. CAP was responsible for $2 \%$ of these cases in Atlanta and 3\% in Baltimore for an estimated incidence of 0.51 cases per 100,000 and 0.54 cases per 100,000 , respectively. Clinical and outcome data regarding patients with MRSA CAP were not available.

KLEVENS et al. [32] also reported that the incidence of CAMRSA infections (based on population-based surveillance in nine sites participating in the Active Bacterial Core surveillance from July 2004 through December 2005) was 4.6 cases per 100,000 . Incidence varied among age groups. A lower incidence was found between the age group 2-17 yrs (median 0.7 per 100,000 cases), and a higher incidence was found among the age groups 35-64 yrs (median 6.5 per 100,000 cases) and $>65$ yrs (8.9 per 100,000 cases). CAP accounted for $14.0 \%$ of CA-MRSA infections for an estimated incidence of 0.64 cases per 100,000. Mortality among patients with CA-MRSA infections was 0.5 cases per 100,000. The corresponding figure for MRSA CAP was not reported. However, it was reported that the overall mortality was higher for patients with septic shock $(55.6 \%)$ and pneumonia $(32.4 \%)$ than patients with other CAMRSA related infections (6.2-19.3\%).

Finally, a survey in US hospitals between 2002 and 2003, which included $\sim 2,200$ patients with culture positive CAP requiring hospitalisation, reported that MRSA was responsible for $8.9 \%$ of all cases and $34.8 \%$ of staphylococcal CAP [33]; the characteristics and outcomes of these patients were not reported. The same study reported that $S$. aureus was responsible for $25.5 \%$ of cases, being the dominant pathogen, followed by Pseudomonas aeruginosa (17.1\%), a figure similar to the one reported for nosocomial and ventilator associated pneumonia.

\section{Case reports of MRSA CAP}

Data for 114 patients were retrieved [34-104]; data on outcomes were available for 110 patients. 23 patients had CAP secondary to another infection. The demographical and clinical characteristics and outcomes of these patients are shown in table 1 (data were not available for all patients).

The mean \pm SD and median (range) age of patients with MRSA CAP was $25.5 \pm 20.3$ and 21 (0-83), respectively. 75 (69\%) out of 109 patients were aged $<35$ yrs and 59\% were males. Risk factors for CA-MRSA colonisation were reported for 32 patients.

Influenza like illness and documented influenza infection was reported in $41 \%$ and $21 \%$ of patients, respectively. Tachypnoea was the most commonly reported symptom (92\%), followed by fever $(89 \%)$, shock $(56 \%)$, cough $(58 \%)$, haemoptysis $(29 \%)$, chest pain $(19 \%)$, gastro-intestinal symptoms $(18 \%)$, rash $(15 \%)$ and confusion (13\%). All reported patients were admitted to the hospital. The reasons for admission are summarised in table 1. Pneumonia was considered severe for $85(86 \%)$ out of 99 patients.

Laboratory findings were not reported consistently in these case reports. Leukopenia was reported in $26(45 \%)$ patients, while thrombocytopenia was reported in 21 (68\%) patients. Liver and kidney function tests, as well as arterial oxygen saturation or blood gases analyses, were rarely reported.

The majority of patients had multilobar consolidations or bilateral lung infiltrates (69 (75\%) out of 92 patients) either at presentation or during the following days. Pleural effusions, including cases with empyema, were seen in 33 (34\%) patients. Computed tomography and lung biopsy showed evidence of necrotising pneumonia in $51(77 \%)$ out of 66 patients.

All but two patients, for whom data was available, received antibiotics within hours after admission; 14 patients had also received antibiotics prior to admission. Appropriate antibiotics were administered in $37(47 \%)$ out of 79 patients. Modifications in the antibiotic regimen were necessary for $42(62 \%)$ out of 68 patients, reflecting changes for inappropriate therapy and treatment failures. No differences were seen in antibiotic administration for patients who died and patients who survived, except for aminoglycosides in patients who died $(\mathrm{p}<0.001)$.

The majority of patients required ICU care (78 (76.5\%) out of 102 patients). Inotropic support for circulatory failure was necessary for $49(65 \%)$ patients and mechanical ventilation for respiratory support was necessary for $55(67 \%)$ patients. Other adjunctive therapies included extracorporeal membrane oxygenation, corticosteroids, activated protein C, i.v. immunoglobulin, surgical drainage of pleural effusion or empyemas and heparin.

Multi-organ failure developed in 35 (44\%) patients and acute respiratory distress syndrome in 19 (23.5\%) patients. Other complications included pneumothorax and pneumatoceles, deep venous thrombosis, acidosis, disseminated intravascular 


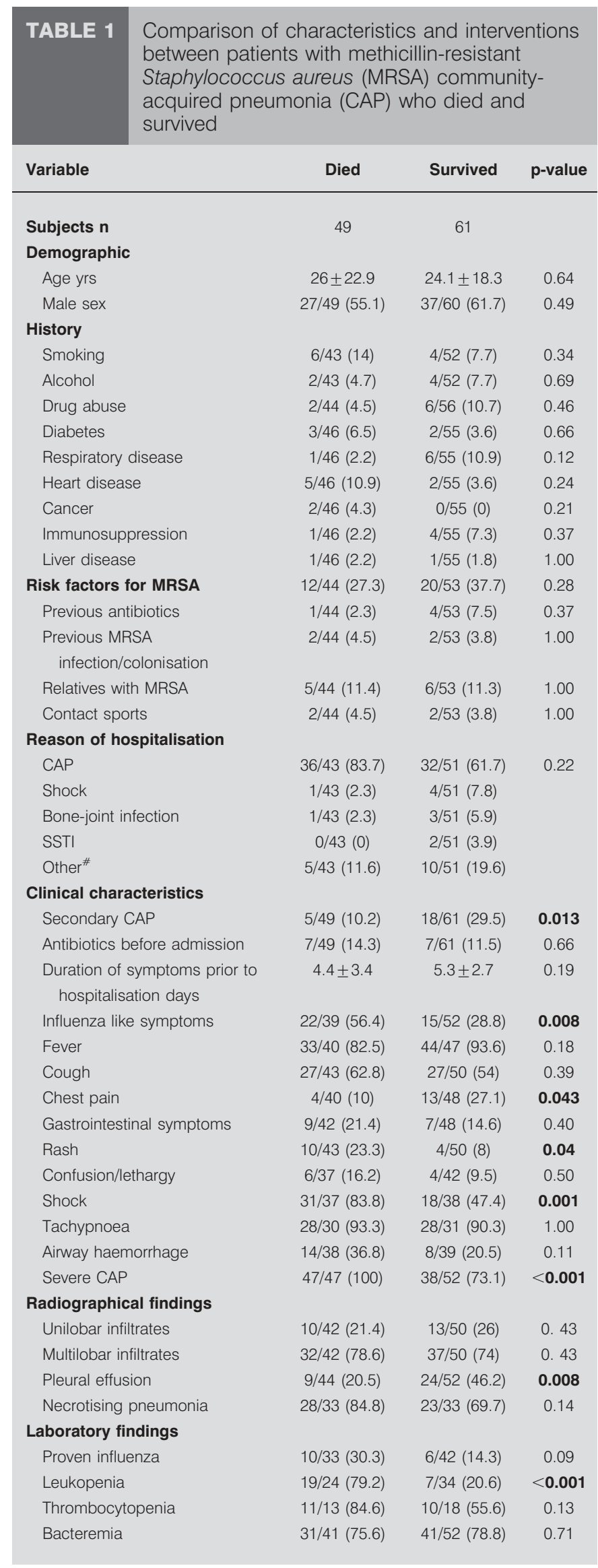

\begin{tabular}{|c|c|c|c|}
\hline Continued & & & \\
\hline Variable & Died & Survived & p-value \\
\hline \multicolumn{4}{|l|}{ Interventions } \\
\hline Admission to ICU & $47 / 48(97.9)$ & $31 / 54(57.4)$ & $<0.001$ \\
\hline Mechanical ventilation & $34 / 38(89.5)$ & $21 / 44(47.7)$ & $<0.001$ \\
\hline $\begin{array}{l}\text { Glycopeptides/linezolid before } \\
\text { culture }\end{array}$ & $16 / 39(41)$ & $17 / 46(37)$ & 0.70 \\
\hline Appropriate empiric therapy & $16 / 33(48.5)$ & $21 / 46(45.7)$ & 0.80 \\
\hline Treatment changes & 13/25 (52) & $29 / 43(67.4)$ & 0.21 \\
\hline Adjunctive therapy & $21 / 38(55.3)$ & 19/27 (70.4) & 0.22 \\
\hline ECMO & $3 / 38(7.9)$ & 9/27 (33.3) & 0.02 \\
\hline Activated protein C & 4/38 (10.5) & 3/27 (11.1) & 1.00 \\
\hline IVIG & 2/38 (5.3) & $4 / 27(14.8)$ & 0.22 \\
\hline Drainage/surgery & 8/38 (21.1) & $4 / 27(14.8)$ & 0.75 \\
\hline \multicolumn{4}{|l|}{ Complications } \\
\hline ARDS & $15 / 36(41.7)$ & $4 / 45(8.9)$ & 0.001 \\
\hline DVT & $0 / 36(0)$ & $4 / 44(9.1)$ & 0.12 \\
\hline Pneumocele/pneumothorax & 5/36 (13.9) & $5 / 44(11.4)$ & 0.75 \\
\hline Acidosis & 5/36 (13.9) & $1 / 44(2.3)$ & 0.09 \\
\hline DIC & 6/36 (16.7) & 1/44 (2.3) & 0.042 \\
\hline Multi-organ failure & 25/36 (69.4) & 10/44 (22.7) & $<0.001$ \\
\hline \multicolumn{4}{|l|}{ Outcomes } \\
\hline Duration of hospitalisation days & $8.3 \pm 11.7$ & $38.1 \pm 25$ & $<0.001$ \\
\hline Duration of ICU stay days & $6.8 \pm 9.7$ & $18.9 \pm 13.6$ & 0.003 \\
\hline
\end{tabular}

Data are presented as mean \pm SD or $n / N$ available (\%), unless otherwise stated. SSTI: skin and soft tissue infection; ICU: intensive care unit; ECMO: extracorporeal membrane oxygenation; IVIG: intravenous immunoglobulins; ARDS: acute respiratory distress syndrome; DVT: deep vain thrombosis; DIC: disseminated intravascular coagulation. ${ }^{*}$ : including DVT, meningitis, endocarditis, gastroenteritis, fever and noncutaneous abscesses; " : including heparin, corticosteroids, haemofiltration, transfusions and surgical procedures. The bold entries refer to values of statistical significance.

coagulation, digital necrosis, abscess formation, WaterhouseFriederichsen syndrome, secondary hospital infections, cerebral infarcts due to septic emboli, and cardiac arrhythmias or arrest.

Data on outcomes were available for 110 patients. Table 2 summarises the included patients according to age and outcome. Pneumonia improved in 61 patients; 49 (44.5\%) died. The median time from symptom onset to death and from hospital admission to death was 8 (3-47) and 3 (1-51) days, respectively. The median duration of hospitalisation for all patients was 10 (1-108) days; the corresponding ICU figure was 3.5 (1-42) days.

The univariate analysis showed that multi-organ failure $(\mathrm{p}<0.001)$, leukopenia $(\mathrm{p}<0.001)$, admission to ICU $(\mathrm{p}<0.001)$, mechanical ventilation $(\mathrm{p}<0.001)$, use of aminoglycosides after culture results $(p<0.001)$, shock $(p=0.001)$, acute respiratory distress syndrome $(p=0.001)$, influenza like symptoms $(p=0.008)$, disseminated intravascular coagulation $(p=0.042)$ and rash $(p=0.04)$ were the factors associated with death. However, secondary CAP $(p=0.013)$, pleural effusion $(p=0.008)$, chest pain $(p=0.043)$ and extracorporeal membrane oxygenation $(p=0.02)$ were associated with survival. A subset analysis that included only articles published from 2005 and onwards resulted in similar outcomes with a few differences. In this analysis, chest pain 


\begin{tabular}{lccc} 
TABLE 2 & $\begin{array}{l}\text { Distribution of patients with methicillin-resistant } \\
\text { Staphylococcus aureus community-acquired } \\
\text { pneumonia according to age and outcome }\end{array}$ \\
\hline Age group & Died & Survived & p-value \\
\hline $\mathbf{0 - 2}$ yrs & $8 / 49(16.3)$ & $11 / 60(18.3)$ & \\
$\mathbf{3 - 1 6}$ yrs & $16 / 49(32.7)$ & $15 / 60(25)$ & \\
$\mathbf{1 7 - 3 5}$ yrs & $11 / 49(22.4)$ & $14 / 60(23.3)$ & 0.38 \\
$\mathbf{3 5 - 6 5}$ yrs & $10 / 49(20.4)$ & $19 / 60(31.7)$ & \\
$\mathbf{7 6 5}$ yrs & $4 / 49(8.2)$ & $1 / 60(1.7)$ & \\
\hline
\end{tabular}

Data are presented as $\mathrm{n} / \mathrm{N}$ available (\%), unless otherwise stated.

$(p=0.144)$ and rash $(p=0.111)$ were not associated with death, while thrombocytopenia was $(p=0.043)$.

Data on toxin carriage was available mainly for PVL (76 strains), while data for other toxins were rarely reported. Data for PFGE typing were available for 37 strains. USA 300 was the commoner pattern identified (26 out of 37 strains) followed by the Queensland clone (nine out of 37). All strains for which PFGE type was available were PVL positive. 35 strains contained the SCCmec type IV and four strains contained the SCCmec type V. Data regarding other molecular typing technique classification were not reported regularly. The majority of the isolated strains were only resistant to oxacillin or methicillin; resistance to macrolides and fluoroquinolones was also reported, while resistance to clindamycin, trimethoprime-sulfamethoxazole and fusidic acid was rare. None of these strains were resistant to linezolid and vancomycin.

\section{Case series of MRSA CAP}

Seven case series have been published [105-111]. The characteristics and outcomes of patients reported in these case series are shown in table 3. A total of 98 patients with MRSA CAP were included in these series. Of these, $52 \%$ of patients were male and $31 \%$ (for whom data was available) had risk factors for CA-MRSA. Influenza like symptoms was present in $57 \%$ of patients; influenza infection was documented by culture or serology in 38\%. Radiographic or autopsy findings of necrotising pneumonia were reported for $61 \%$ of patients. All patients who did not die in the emergency department or during transfer to another hospital were admitted to the hospital, of which $85 \%$ required ICU treatment. The duration of hospitalisation varied between studies but, in general, the median length of stay was prolonged ( $>13$ days). Finally, overall mortality was 39\%; data regarding mortality attributable to MRSA CAP was not available.

The largest cohort included 51 patients with primary staphylococcal CAP [105]. This cohort included unsolicited case reports submitted to the CDC and requested case reports from infectious disease specialists participating in an Infectious Disease Society of America (IDSA) Emerging Infections Network survey. Identification of $S$. aureus was performed with the Staphaurex latex agglutination test, catalase and coagulase production. All available isolates underwent PFGE typing; toxin production was verified by PCR assays. 47 patients had positive cultures for $S$. aureus (isolated from respiratory secretions $(60 \%)$, blood $(38 \%)$, pleural fluid $(23 \%)$ and lung tissue (9\%)) while four additional patients had a positive $S$. aureus immunohistochemistry result at autopsy and pathology; 37 of these isolates were MRSA. Out of the 17 MRSA strains available for further analysis 16 were PVL positive and belonged to the USA 300 PFGE type. The remaining isolate was a PVL negative USA100 strain, a pattern that is most commonly found in hospital acquired infections.

The characteristics of patients with MRSA CAP were not reported separately. However, it was reported that appropriate empiric therapy was instituted in $43 \%$ of MRSA patients and $100 \%$ of MSSA patients. An interesting finding of this study was that empiric antibiotic therapy was initiated sooner in patients who died than those who survived (median 2 versus 5 days). In addition, median length of stay was shorter for influenza positive than influenza negative patients (16 versus 8.5 days). Leukopenia was associated with death in multivariate analysis. KALLEN et al. [105] emphasised that the limitations of their study were its retrospective design, the possibility of reporting only more severe cases, the isolation of $S$. aureus mainly from sputum specimens that increased the probability to include patients simply colonised with $S$. aureus and the difficulty in collecting data regarding a preceding or concomitant influenza infection.

The remaining descriptive case series included only a small number of patients each (from five to 12 patients) [106-111]. Therefore, strong conclusions could not be made from the individual studies. Figure 2 summarises the annual published reports of MRSA CAP.

\section{DISCUSSION}

Studies regarding MRSA CAP are lacking. The limited available data shows that MRSA should not be considered a frequent cause of CAP. Its estimated incidence was $0.51-0.64$ cases per 100,000 , while the incidence of CAP was 266.8 per 100,000 population in 1991 and 198 cases per 100,000 population in 2004-2005 [119, 120]. However, studies suggest that the incidence of MRSA CAP may be rising, especially in cases complicated with pleural effusion [114-116]. The most worrying findings come from one study that shows a prevalence of $8.9 \%$ among hospitalised patients with culture positive CAP [33]. Should these findings be verified in other studies, modifications to the guidelines for treatment of CAP should be considered to incorporate coverage of MRSA in the empirical regimen, at least for those requiring hospitalisation [121].

The published data also suggest that MRSA CAP is a severe disease. Mortality in the individual case series [105-111] was $20-60 \%$, while mortality in case reports [34-104] was $44.5 \%$. The estimated overall mortality in patients with CAP is $5-9 \%$; the corresponding figure in patients with severe CAP was 9$27 \%$ [122]. In addition, the majority of patients with MRSA $\mathrm{CAP}$ in these reports required ICU treatment. Further evidence supporting the notion of severe disease is provided by the short period from symptom onset or diagnosis of pneumonia to death. However, since most of the published studies are case reports or small case series, and series reporting severe disease are more likely to be published, this finding may not reflect the true burden of the disease. 
TABLE 3 Case series with methicillin-resistant Staphylococcus aureus (MRSA) community-acquired pneumonia (CAP) patients published after 1985

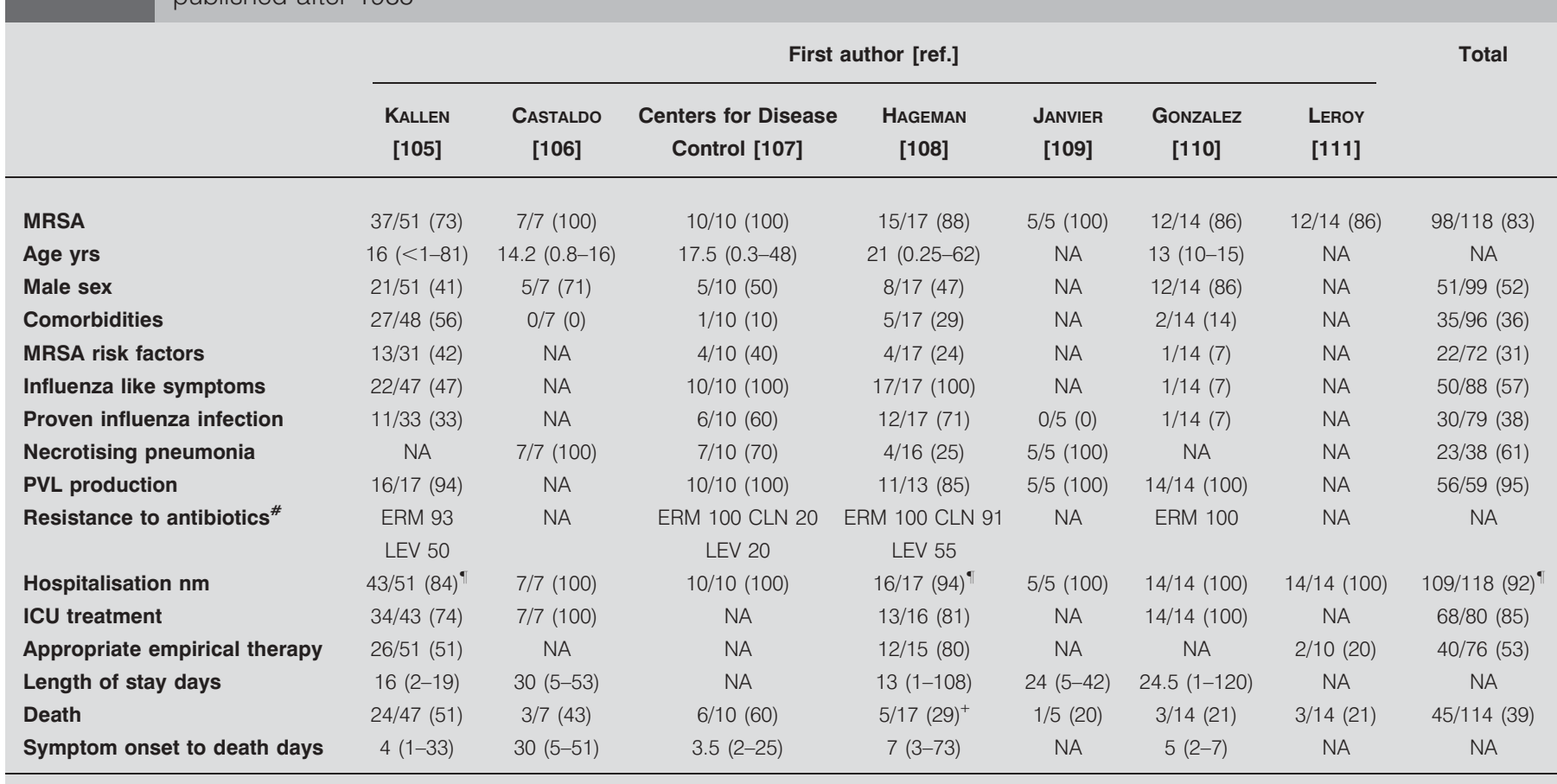

Data are presented as n/total patients (\%) or median (range). The data for resistance to antibiotics is presented as per cent. PVL: Panton-Valentine leukocidin; ICU: intensive care unit; NA: not available/applicable; ERM: erythromycin; LEV: levofloxacin; CLN: clindamycin. ${ }^{*}$ : strains were sensitive to linezolid, vancomycin, rifampin and gentamycin;

$\because$ : the remaining patients died in the emergency department or during transfer to another hospital; ${ }^{+}$: four out of five deceased patients had MRSA pneumonia.

The main characteristic of the patients reported in the literature was the severity of pneumonia. The aetiology of severe CAP is diverse. Therefore, the severity of pneumonia cannot be associated with MRSA. However, a combination of severe CAP and younger age could be a clue pointing towards MRSA (or S. aureus) infection. Finally, although present in only $32.5 \%$ of patients in our study, physicians should seek to identify risk factors for MRSA infections. These, in addition to the recommendations of IDSA of preceding influenza infection and chest radiographs with cavitary lesions without risk factors for aspiration, should prompt physicians to suspect MRSA as the causative organism of pneumonia.

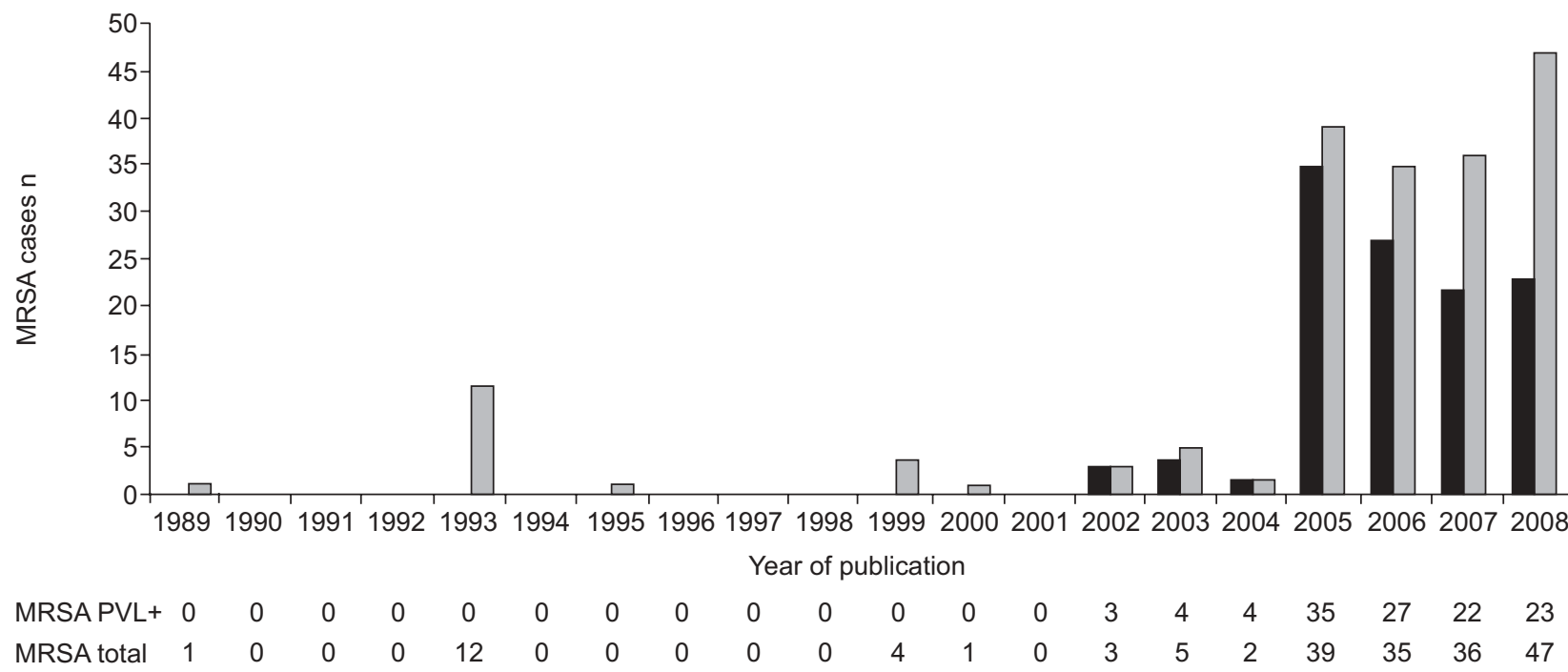

FIGURE 2. Summary of the annual published reports of methicillin-resistant S. aureus (MRSA) cases between 1989 and 2008. $\square$ : MRSA total; Valentine leukocidin (PVL) positive. 
Few patients received an appropriate initial antibiotic denoting that physicians do not consider MRSA as a frequent cause of CAP. The low incidence of MRSA CAP in two studies reporting the incidence of MRSA infections may support this view $[31,32]$. Although published guidelines support the use of vancomycin or linezolid in cases of severe CAP to extend antibiotic coverage [121], physicians do not seem to adhere to these guidelines since in the majority of cases these antibiotics were administered only if MRSA was isolated or a similar case was recently encountered in the same hospital. Nevertheless, appropriate antibiotic coverage was not associated with improved outcomes in these cases. Appropriate initial antibiotic therapy and early antibiotic administration, as soon as $4 \mathrm{~h}$ following admission, have been associated with better outcomes in patients with CAP $[123,124]$. In our study, data regarding timing of antibiotic administration was not available. Furthermore, patients were hospitalised 4-5 days following initiation of symptoms, a fact that probably limits the value of appropriate therapy. In addition, the majority of included patients had severe CAP; it is debatable whether antibiotics or adjunctive therapies have a greater impact on infection outcomes in such cases [125]. Another issue that should be emphasised is that the current study is probably underpowered to show the real value of appropriate therapy. And last but not least, physicians should consider the role of toxin production and regulation (mainly PVL in this study) on outcomes of staphylococcal infections.

The issue of appropriate versus optimal treatment in cases of MRSA CAP has not been studied. Vancomycin and linezolid are currently considered the most appropriate treatment options for MRSA pneumonia [121]. Linezolid has been shown to be more effective than vancomycin in retrospective analyses of HAP [126], but a meta-analysis did not confirm the results [127]. In addition, linezolid was associated with less toxin release [128]. CA-MRSA is currently susceptible to fluoroquinolones, clindamycin, trimethoprime-sulfamethoxazole, rifampin and possibly macrolides. The effectiveness of newer antimicrobial agents, such as tigecycline, ceftobiprole and newer lipoglycopeptides, has not been evaluated in MRSA CAP. Comparative trials regarding treatment options of MRSA CAP are not available.

An interesting finding was that influenza like symptoms were frequently present and started shortly before the diagnosis of CAP. None of the patients reported the biphasic illness classically described for CAP following influenza infection. This, in addition to the low sensitivity of the available influenza tests and the relatively infrequent use of these tests by physicians, may lead to a dual implication: MRSA CAP has either similar symptoms with influenza (at least at the beginning), or the two infections develop simultaneously. Finally, MRSA CAP can be considered as a complication of influenza.

The role of PVL in the outcome of MRSA CAP could not be determined in this study because data was not available for patients with PVL negative strains. Although the role of PVL in the development and outcome of staphylococcal disease is debatable in humans, a recent murine model suggested that PVL plays a major role in the development and outcome of pneumonia [129]. This study also showed that the virulence of PVL positive strains is enhanced by the presence of other toxins, especially staphylococcal protein A. Furthermore, the presence of PVL genes up-regulated several genes encoding proteins, known as microbial surface components recognising adhesive matrix molecules, which lead to enhanced tissue adherence and colonisation, thus contributing to the virulence of PVL positive strains.

In conclusion, the limited available evidence shows that MRSA CAP seems to be an infrequent infection. However, there is data suggesting an increase in the incidence of MRSA infections over the last few years. The majority of published cases involved severe disease and were associated with significant mortality. Physicians should consider MRSA more frequently among the possible pathogens in patients with severe CAP. Additional population based studies are needed to identify the true burden of MRSA CAP and the role of antibiotics and other adjunctive therapies.

\section{STATEMENT OF INTEREST}

None declared.

\section{REFERENCES}

1 Archer GL. Staphylococcus aureus: a well-armed pathogen. Clin Infect Dis 1998; 26: 1179-1181.

2 Zetola N, Francis JS, Nuermberger EL, et al. Communityacquired meticillin-resistant Staphylococcus aureus: an emerging threat. Lancet Infect Dis 2005; 5: 275-286.

3 Kollef MH, Micek ST. Methicillin-resistant Staphylococcus aureus: a new community-acquired pathogen? Curr Opin Infect Dis 2006; 19: 161-168.

4 Kowalski TJ, Berbari EF, Osmon DR. Epidemiology, treatment, and prevention of community-acquired methicillin-resistant Staphylococcus aureus infections. Mayo Clin Proc 2005; 80: 1201-1207.

5 Guest JF, Morris A. Community-acquired pneumonia: the annual cost to the National Health Service in the United Kingdom. Eur Respir J 1997; 10: 1530-1534.

6 Niederman MS, McCombs JS, Unger AN, et al. The cost of treating community-acquired pneumonia. Clin Ther 1998; 20: 820-837.

7 Warren DK, Shukla SJ, Olsen MA, et al. Outcome and attributable cost of ventilator-associated pneumonia among intensive care unit patients in a suburban medical center. Crit Care Med 2003; 31: 1312-1317.

8 Gosbell IB. Epidemiology, clinical features and management of infections due to community methicillin-resistant Staphylococcus aureus (cMRSA). Intern Med J 2005; 35: Suppl. 2, S120-S135.

9 Bradley SF. Staphylococcus aureus pneumonia: emergence of MRSA in the community. Semin Respir Crit Care Med 2005; 26: 643-649.

10 Micek ST, Kollef KE, Reichley RM, et al. Health care-associated pneumonia and community-acquired pneumonia: a single-center experience. Antimicrob Agents Chemother 2007; 51: 3568-3573.

11 Morgan MS. Diagnosis and treatment of Panton-Valentine leukocidin (PVL)-associated staphylococcal pneumonia. Int J Antimicrob Agents 2007; 30: 289-296.

12 Schultz KD, Fan LL, Pinsky J, et al. The changing face of pleural empysemas in children: epidemiology and management. Pediatrics 2004; 113: 1735-1740.

13 Feldman C, Ross S, Mahomed AG, et al. The aetiology of severe community-acquired pneumonia and its impact on initial, empiric, antimicrobial chemotherapy. Respir Med 1995; 89: 187-192.

14 Rubinstein E, Kollef MH, Nathwani D. Pneumonia caused by Methicillin-resistant Staphylococcus aureus. Clin Infect Dis 2008; 46: Suppl. 5, S378-S385. 
15 Gillet $Y$, Vanhems $P$, Lina G, et al. Factors predicting mortality in necrotizing community-acquired pneumonia caused by Staphylococcus aureus containing Panton-Valentine leukocidin. Clin Infect Dis 2007; 45: 315-321.

16 Gillet $\mathrm{Y}$, Issartel B, Vanhems $\mathrm{P}$, et al. Association between Staphylococcus aureus strains carrying gene for Panton-Valentine leukocidin and highly lethal necrotising pneumonia in young immunocompetent patients. Lancet 2002; 359: 753-759.

17 Lina G, Piémont Y, Godail-Gamot F, et al. Involvement of Panton-Valentine leukocidin-producing Staphylococcus aureus in primary skin infections and pneumonia. Clin Infect Dis 1999; 29: $1128-1132$.

18 Huijsdens XW, van Santen-Verheuvel MG, Spalburg E, et al. Multiple cases of familial transmission of community-acquired methicillin-resistant Staphylococcus aureus. J Clin Microbiol 2006; 44: 2994-2996.

19 Centers for Disease Control and Prevention (CDC). Methicillinresistant Staphylococcus aureus infections in correctional facilities - Georgia, California, and Texas, 2001-2003. MMWR Morb Mortal Wkly Rep 2003; 52: 992-996.

20 Diep BA, Sensabaugh GF, Somboona NS, et al. Widespread skin and soft-tissue infections due to two methicillin-resistant Staphylococcus aureus strains harboring the genes for PantonValentine leucocidin. J Clin Microbiol 2004; 42: 2080-2084.

21 Lindenmayer JM, Schoenfeld S, O'Grady R, et al. Methicillinresistant Staphylococcus aureus in a high school wrestling team and the surrounding community. Arch Intern Med 1998; 158: 895-899.

22 Kazakova SV, Hageman JC, Matava M, et al. A clone of methicillin-resistant Staphylococcus aureus among professional football players. N Engl J Med 2005; 352: 468-475.

23 Campbell KM, Vaughn AF, Russell KL, et al. Risk factors for community-associated methicillin-resistant Staphylococcus aureus infections in an outbreak of disease among military trainees in San Diego, California, in 2002. J Clin Microbiol 2004; 42: 4050-4053.

24 Outbreaks of community-associated methicillin-resistant Staphylococcus aureus skin infections - Los Angeles County, California, 2002-2003. MMWR Morb Mortal Wkly Rep 2003; 52: 88

25 Moreno F, Crisp C, Jorgensen JH, et al. Methicillin-resistant Staphylococcus aureus as a community organism. Clin Infect Dis 1995; 21: 1308-1312.

26 Charlebois ED, Perdreau-Remington F, Kreiswirth B, et al. Origins of community strains of methicillin-resistant Staphylococcus aureus. Clin Infect Dis 2004; 39: 47-54.

27 Charlebois ED, Bangsberg DR, Moss NJ, et al. Population-based community prevalence of methicillin-resistant Staphylococcus aureus in the urban poor of San Francisco. Clin Infect Dis 2002; 34: 425-433.

28 Baggett HC, Hennessy TW, Rudolph K, et al. Community-onset methicillin-resistant Staphylococcus aureus associated with antibiotic use and the cytotoxin Panton-Valentine leukocidin during a furunculosis outbreak in rural Alaska. J Infect Dis 2004; 189: 1565-1573.

29 Landen MG, McCumber BJ, Asay ED, et al. Outbreak of boils in an Alaskan village: a case control study. West J Med 2000; 172 235-239.

30 Centers for Disease Control and Prevention (CDC). Communityassociated methicillin-resistant Staphylococcus aureus infections in Pacific Islanders - Hawaii, 2001-2003. MMWR Morb Mortal Wkly Rep 2004; 53: 767-770.

31 Fridkin SK, Hageman JC, Morrison M, et al. Methicillin-resistant Staphylococcus aureus disease in three communities. N Engl J Med 2005; 352: 1436-1444.

32 Klevens RM, Morrison MA, Nadle J, et al. Invasive methicillinresistant Staphylococcus aureus infections in the United States. JAMA 2007; 298: 1763-1771.

33 Kollef MH, Shorr A, Tabak YP, et al. Epidemiology and outcomes of health-care-associated pneumonia. Results from a large
US Database of culture-positive pneumonia. Chest 2005; 128 3854-3862.

34 Baldwin LN, Lowe AD. Panton-Valentine Leukocidin associated with community acquired methicillin resistant Staphylococcus aureus: a case report and review of interim guidelines. Anaesthesia 2008; 63: 764-766.

35 Dickson RP, Martinez SM, Ortiz JR. A Case of rapidly progressive necrotizing pneumonia caused by communityacquired methicillin-resistant Staphylococcus aureus. Respir Care 2008; 53: 1223-1226.

36 Ebert MD, Sheth S, Fishman EK. Necrotizing pneumonia caused by community-acquired methicillin-resistant Staphylococcus aureus: an increasing cause of "mayhem in the lung". Emerg Radiol 2009; 16: 159-162.

37 Ho PL, Wong MP, Lai EL, et al. DNA typing of cytological samples for retrospective identification of an early case of Panton-Valentine Leucocidin-positive, community-associated methicillin-resistant Staphylococcus aureus pneumonia. J Clin Micobiol 2008; 46: 2457-2458.

38 Ito T, Iijima M, Fukushima $\mathrm{T}$, et al. Pediatric pneumonia death caused by community-acquired methicillin-resistant Staphylococcus aureus, Japan. Emerg Infect Dis 2008; 14: 1312-1314.

39 Lee YP, Hoi WH, Wong RC. A case of Myopericarditis in a patient with methicillin-resistant Staphylococcus aureus community-acquired pneumonia. Ann Acad Med Singapore 2008; 37: $243-242$

40 Martino JL, McMillian WD, Polish LB, et al. Communityacquired methicillin-resistant Staphylococcus aureus pneumonia. Respir Med 2008; 102: 932-934.

41 Tong SY, Anstey NM, Lum GD, et al. Fatal communityassociated methicillin-resistant Staphylococcus aureus pneumonia after influenza. Med J Aust 2008; 188: 61.

42 Valentini $\mathrm{P}$, Parisi G, Monaco $\mathrm{M}$, et al. An uncommon presentation for a severe invasive infection due to methicillinresistant Staphylococcus aureus clone USA300 in Italy: a case report. Ann Clin Microbiol Antimicrob 2008; 7: 11.

43 Yee-Guardino S, Kumar D, Abughali N, et al. Recognition and treatment of neonatal community-associated MRSA pneumonia and bacteremia. Pediatr Pulmonol 2008; 43: 203-205.

44 Adam H, McGeer A, Simor A. Fatal case of post-influenza, community-associated MRSA pneumonia in an Ontario teenager with subsequent familial transmission. Can Commun Dis Rep 2007; 33: 45-48

45 Agwu A, Brady KM, Ross T, et al. Cholera-like diarrhea and shock associated with community-acquired methicillin-resistant Staphylococcus aureus (USA400 clone) pneumonia. Pediatr Infect Dis J 2007; 26: 271-273.

46 Asnis D, Haralambou G, Tawiah P. Methicillin-resistant Staphylococcus aureus necrotizing pneumonia arising from an infected episiotomy site. Obstetr Gynecol 2007; 110: 188.

47 Balis E, Diacaki C, Tselioti $\mathrm{P}$, et al. Community-acquired pneumonia and bacteremia due to methicillin-resistant Staphylococcus aureus carrying Panton-Valentine-leukocidin gene in Greece: two case reports and literature review. J Chemother 2007; 19: 703-708.

48 Creech $C B$, Johnson BG, Bartilson RE, et al. Increasing use of extracorporeal life support in methicillin-resistant Staphylococcus aureus sepsis in children. Pediatr Crit Care Med 2007; 8: 231-235.

49 Magira EE, Zervakis D, Routsi C, et al. Community-acquired methicillin-resistant Staphylococcus aureus carrying Panton-Valentine leukocidin genes: a lethal cause of pneumonia in an adult immunocompetent patient. Scand J Infect Dis 2007; 39: 466-469.

50 Nourse C, Starr M, Munckhof W. Community-acquired methicillin-resistant Staphylococcus aureus causes severe disseminated infection and deep venous thrombosis in children: literature review and recommendations for management. $J$ Paediatr Child Health 2007; 43: 656-661. 
51 Okhuysen-Cawley R, Prodhan P, Imamura M, et al. Management of abdominal compartment syndrome during extracorporeal life support. Pediatr Crit Care Med 2007; 8: 177-179.

52 Quadri AM, Hock YL. Pulmonary pathology of Panton-Valentine leukocidin gene carrying methicillin-resistant Staphylococcus aureus pneumonia. Histopathology 2007; 51: 712-713.

53 Risson DC, O'Connor ED, Guard RW, et al. A fatal case of necrotising pneumonia due to community-associated methicillin-resistant Staphylococcus aureus. Med J Aust 2007; 186: 479-480.

54 Rotas M, McCalla S, Liu C, et al. Methicillin-resistant Staphylococcus aureus necrotizing pneumonia arising from an infected episiotomy site. Obstet Gynecol 2007; 109: 533-536.

55 Tronci M, Parisi G, Pantosti A, et al. CA-MRSA strain with decreased vancomycin susceptibility as a cause of serious invasive infection in an immunocompetent adolescent. Clin Microbiol Infect 2007; 13: Suppl. 1, S449.

56 Vayalumkal JV, Whittingham $\mathrm{H}$, Vanderkooi $\mathrm{O}$, et al. Necrotizing pneumonia and septic shock: suspecting CAMRSA in patients presenting to Canadian emergency departments. CJEM 2007; 9: 300-303.

57 Chua AP, Lee KH. Fatal bacteraemic pneumonia due to community-acquired methicillin-resistant Staphylococcus aureus. Singapore Med J 2006; 47: 546-548.

58 Enayet I, Nazeri A, Johnson LB, et al. Community-associated methicillin-resistant Staphylococcus aureus causing chronic pneumonia. Clin Infect Dis 2006; 42: e57-e60.

59 Fortunov RM, Hulten KG, Hammerman WA, et al. Communityacquired Staphylococcus aureus infections in term and near-term previously healthy neonates. Pediatrics 2006; 118: 874-881.

60 Garnier F, Tristan A, François B, et al. Pneumonia and new methicillin-resistant Staphylococcus aureus clone. Emerg Infect Dis 2006; 12: 498-500.

61 Gerogianni I, Mpatavanis G, Gourgoulianis K, et al. Combination of staphylococcal chromosome cassette SCCmec type V and Panton-Valentine leukocidin genes in a methicillin-resistant Staphylococcus aureus that caused necrotizing pneumonia in Greece. Diagn Microbiol Infect Dis 2006; 56: 213-216.

62 Hampson FG, Hancock SW, Primhak RA. Disseminated sepsis due to a Panton-Valentine leukocidin producing strain of community acquired meticillin resistant Staphylococcus aureus and use of intravenous immunoglobulin therapy. Arch Dis Child 2006; 91: 201.

63 Jeyaratnam D, Reid C, Kearns A, et al. Community associated MRSA: an alert to paediatricians. Arch Dis Child 2006; 91: 511-512.

64 Jones TF, Creech CB, Erwin P, et al. Family outbreaks of invasive community-associated methicillin-resistant Staphylococcus aureus infection. Clin Infect Dis 2006; 42: e76-e78.

65 Michalopoulos A, Falagas ME. Multi-systemic methicillin resistant Staphylococcus aureus (MRSA) community-acquired infection. Med Sci Monit 2006; 12: CS39-CS43.

66 Sabbatani F, Manfredi R, Marinacci G, et al. Communityacquired pneumonia and sepsis caused by multiresistant Staphylococcus aureus strain resulting in severe and long-lasting multiple organ inflammatory involvement. Eur J Inflam 2006; 4: 117-123.

67 Söderquist B, Berglund C, Strålin K. Community-acquired pneumonia and bacteremia caused by an unual methicillinresistant Staphylococcus aureus (MRSA) strain with sequence type 36, staphylococcal cassette chromosome mec type IV and Panton-Valentine leukocidin genes. Eur J Clin Microbiol Infect Dis 2006; 25: 604-606.

68 Adem PV, Montgomery CP, Husain AN, et al. Staphylococcus aureus sepsis and the Waterhouse-Friderichsen syndrome in children. N Engl J Med 2005; 353: 1245-1251.

69 Conly J, Gilbert M, Zahang K, et al. Rapidly progressive fatal necrotizing pneumonitis (FNP) secondary to Panton-Valentine leukocidin (PVL)+ SCCmec type IVa community-acquired methicillin-resistant S. aureus (CAMRSA) - a harbinger of the future? Can J Infect Dis Med Microbiol 2005; 16: 109-110.

70 Francis JS, Doherty MC, Lopatin U, et al. Severe communityonset pneumonia in healthy adults caused by methicillinresistant Staphylococcus aureus carrying the Panton-Valentine leukocidin genes. Clin Infect Dis 2005; 40: 100-107.

71 Frazee BW, Salz TO, Lambert L, et al. Fatal communityassociated methicillin-resistant Staphylococcus aureus pneumonia in an immunocompetent young adult. Ann Emerg Med 2005; 46 401-404.

72 Hsu LY, Tristan A, Koh TH, et al. Community-associated methicillin-resistant Staphylococcus aureus, Singapore. Emerg Infect Dis 2005; 11: 341-342.

73 Kravitz GR, Dries DJ, Peterson ML, et al. Purpura fulminans due to Staphylococcus aureus. Clin Infect Dis 2005; 40: 941-947.

74 Martin BT, Palasanthiran P, Gosbell IB, et al. Severe childhood pneumonitis caused by the Queensland strain of communityacquired methicillin-resistant Staphylococcus aureus. Med J Aust 2005; 182: 249.

75 McAdams RM, Mazuchowski E, Ellis MW, et al. Necrotizing staphylococcal pneumonia in a neonate. J Perinatol 2005; 25 677-679.

76 Monaco M, Antonucci R, Palange P, et al. Methicillin-resistant Staphylococcus aureus necrotizing pneumonia. Emerg Infect Dis 2005; 11: 1647-1648.

77 Micek ST, Dunne M, Kollef MH. Pleuropulmonary complications of Panton-Valentine leukocidin-positive communityacquired methicillin-resistant Staphylococcus aureus: importance of treatment with antimicrobials inhibiting exotoxin production. Chest 2005; 128: 2732-2738.

78 Peleg AY, Munckhof WJ, Kleinschmidt SL, et al. Life-threatening community-acquired methicillin-resistant Staphylococcus aureus infection in Australia. Eur J Clin Microbiol Infect Dis 2005; 24: 384-387.

79 Schulz P, Allen M, Murray Q, et al. Infections due to communityacquired methicillin-resistant Staphylococcus aureus: an emergent epidemic in Kentucky. J Ky Med Assoc 2005; 103: 194-203.

80 Torell E, Molin D, Tano E, et al. Community-acquired pneumonia and bacteraemia in a healthy young woman caused by methicillin-resistant Staphylococcus aureus (MRSA) carrying the genes encoding Panton-Valentine leukocidin (PVL). Scand J Infect Dis 2005; 37: 902-904.

81 Tseng $\mathrm{MH}$, Wei BH, Lin WJ, et al. Fatal sepsis and necrotizing pneumonia in a child due to community-acquired methicillinresistant Staphylococcus aureus: case report and literature review. Scand J Infect Dis 2005; 37: 504-507.

82 Wang $\mathrm{CM}$, Chuang $\mathrm{CH}$, Chiu $\mathrm{CH}$. Community-acquired disseminated methicillin-resistant Staphylococcus aureus infection: case report and clinical implications. Ann Trop Paediatr 2005; 25: 53-57.

83 Al-Tawfiq JA, Aldaabil RA. Community-acquired MRSA bacteremic necrotizing pneumonia in a patient with scrotal ulceration. J Infect 2005; 51: e241-e243.

84 Miklaševics E, Hæggman S, Balode A, et al. Report on the first PVL-positive community acquired MRSA strain in Latvia. Euro Surveill 2004; 9: 29-30.

85 Peleg AY, Munckhof WJ. Fatal necrotising pneumonia due to community-acquired methicillin-resistant Staphylococcus aureus (MRSA). Med J Aust 2004; 181: 228-229.

86 Boussaud V, Parrot A, Mayaud C, et al. Life-threatening hemoptysis in adults with community-acquired pneumonia due to Panton-Valentine leukocidin-secreting Staphylococcus aureus. Intensive Care Med 2003; 29: 1840-1843.

87 Mongkolrattanothai K, Boyle S, Kahana MD, et al. Severe Staphylococcus aureus infections caused by clonally related 
community-acquired methicillin-susceptible and methicillinresistant isolates. Clin Infect Dis 2003; 37: 1050-1058.

88 Nimmo GR, Playford EG. Community-acquired MRSA bacteraemia: four additional cases including one associated with severe pneumonia. Med J Aust 2003; 178: 245.

89 van der Flier M, van Dijk NB, Fluit AC, et al. Fatal pneumonia in an adolescent due to community-acquired MRSA positive for Panton-Valentine-leukocidin. Ned Tijdschr Geneeskd 2003; 147: 1076-1079.

90 Dufour $\mathrm{P}$, Gillet $\mathrm{Y}$, Bes $\mathrm{M}$, et al. Community-acquired methicillinresistant Staphylococcus aureus infections in France: emergence of a single clone that produces Panton-Valentine leukocidin. Clin Infect Dis 2002; 35: 819-824.

91 Bitzan MM, Nagaraj SK, Georgitis JW, et al. Staphylococcus aureus pneumonia, hyponatremia, hypertension, proteinuria, and hematuria in a 14-year-old boy. Am J Kidney Dis 2000; 35: 354359.

92 Gorak EJ, Yamada SM, Brown JD. Community-acquired methicillin-resistant Staphylococcus aureus in hospitalized adults and children without known risk factors. Clin Infect Dis 1999; 29: 797-800

93 From the Centers for Disease Control and Prevention. Four pediatric deaths from community-acquired methicillin-resistant Staphylococcus aureus - Minnesota and North Dakota, 1997-1999. JAMA 1999; 282: 1123-1125.

94 Vassallo J, Galizia AC, Cuschieri P. Mixed pulmonary infection with Nocardia, Candida, MRSA, and group D Streptococcus species. Postgrad Med J 1996; 72: 680-681.

95 Dicpinigaitis PV, Levy DE, Gnass RD, et al. Pneumonia due to Staphylococcus aureus in a patient with AIDS: review of incidence and report of an atypical roentgenographic presentation. South Med J 1995; 88: 586-590.

96 Brian MJ, Michael A. Community-acquired infection with methicillin-resistant Staphylococcus aureus in Papua New Guinea. Pediatr Infect Dis J 1989; 8: 807-808.

97 Bedoui A, Braham M, Mahjoub B, et al. [Severe community acquired pneumonia due to Staphylococcus aureus in children. About two cases.]. Tunis Med 2006; 84: 666-669.

98 Bruno GJ, Bruno JM, Miyake AA. Community-acquired methicillin-resistant Staphylococcus aureus infection with fatal necrotizing pneumonia from lip abscess: a case report. J Oral Maxillofac Surg 2007; 65: 2350-2353.

99 Descloux E, Mohammedi I, Gillet Y, et al. Necrotizing pneumonia in an adult due to methicillin-resistant Staphylococcus aureus producing Panton-Valentine leukocidin. Reanimation 2007; 16: 256-258

100 Teglia O, Gregorini E, Notario R, et al. Community-acquired methicillin-resistant Staphylococcus aureus. Rev Med Rosario 2007; 73: 76-81.

101 Luque Moreno A, Duran Núñez A, Bergadà Masó A, et al. Community-acquired, methicillin-resistant Staphylococcus aureus acute osteomyelitis and pneumonia. An Pediatr (Barc) 2008; 68: 373-376.

102 Barrios M, Alcolea A, Negreira S, et al. Necrotizing pneumonia due to community-acquired methicillin resistant Staphylococcus aureus in a pediatric patient. Enferm Infecc Microbiol Clin 2008; 26: 398-399.

103 Kuhn C, Markau S, Osten B. [Abscettic pneumonia in a renal transplantation female patient.]. Internist (Berl) 2005; 46: 789-794.

104 Sifuentes-Osornio J, Pérez-Patrigeon S. Sepsis caused by methicillin-resistant Staphylococcus aureus: the shadow of a persistent threat. Rev Invest Clin 2006; 58: 598-607.

105 Kallen AJ, Brunkard J, Moore Z, et al. Staphylococcus aureus community-acquired pneumonia during the 2006 to 2007 influenza season. Ann Emerg Med 2009; 53: 258-365.
106 Castaldo ET, Yang EY. Severe sepsis attributable to communityassociated methicillin-resistant Staphylococcus aureus: an emerging fatal problem. Am Surg 2007; 73: 684-687.

107 Centers for Disease Control and Prevention (CDC). Severe methicillin-resistant Staphylococcus aureus communityacquired pneumonia associated with influenza - Louisiana and Georgia, December 2006-January 2007. MMWR Morb Mortal Wkly Rep 2007; 56: 325-329.

108 Hageman JC, Uyeki TM, Francis JS, et al. Severe communityacquired pneumonia due to Staphylococcus aureus, 2003-04 influenza season. Emerg Infect Dis 2006; 12: 894-899.

109 Janvier J, Elsayed S, Gregson D, et al. Necrotising pneumonia secondary to community-associated methicillin-resistant $S$ aureus (CAMRSA) USA300 strain without evidence of antecedent viral respiratory tract infection. Can J Infect Dis Med Microbiol 2006; 17 310-315.

110 Gonzalez BE, Martinez-Aguilar G, Hulten KG, et al. Severe Staphylococcal sepsis in adolescents in the era of communityacquired methicillin-resistant Staphylococcus aureus. Pediatrics 2005; 115: 642-648

111 Leroy O, Beuscart C, Garo B. Staphylococcal pulmonary infections. Med Mal Infect 1993; 23: 8-15.

112 Johnston BL. Methicillin-resistant Staphylococcus aureus as a cause of community-acquired pneumonia - a critical review. Semin Respir Infect 1994; 9: 199-206.

113 Stankovic C, Mahajan PV, Asmar BI. Methicillin-resistant Staphylococcus aureus as a cause of community-acquired pneumonia. Curr Infect Dis Rep 2007; 9: 223-227.

114 Buckingham SC, King MD, Miller ML. Incidence and etiologies of complicated parapneumonic effusions in children, 1996 to 2001. Pediatr Infect Dis J 2003; 22: 499-504.

115 Schultz KD, Fan LL, Pinsky J, et al. The changing face of pleural empyemas in children: epidemiology and management Pediatrics 2004; 113: 1735-1740.

116 Alfaro C, Fergie J, Purcell K. Emergence of community-acquired Staphylococcus aureus in complicated parapneumonic effusions. Pediatr Infect Dis J 2005; 24: 274-276.

117 Groom AV, Wolsey DH, Naimi TS, et al. Community-acquired methicillin-resistant Staphylococcus aureus in a rural American Indian community. JAMA 2001; 286: 1201-1205.

118 Purcell K, Fergie J. Epidemic of community-acquired methicillinresistant Staphylococcus aureus infections: a 14-year study at Driscoll Children's Hospital. Arch Pediatr Adolesc Med 2005; 159: 980-985.

119 Marston BJ, Plouffe JF, File TM Jr, et al. Incidence of communityacquired pneumonia requiring hospitalization. Results of a population-based active surveillance Study in Ohio. The Community-Based Pneumonia Incidence Study Group. Arch Intern Med 1997; 157: 1709-1718.

120 Trotter CL, Stuart JM, George R, et al. Increasing hospital admissions for pneumonia, England. Emerg Infect Dis 2008; 14 727-733.

121 Mandell LA, Wunderink RG, Anzueto A, et al. Infectious Diseases Society of America/American Thoracic Society consensus guidelines on the management of community-acquired pneumonia in adults. Clin Infect Dis 2007; 44: Suppl. 2, S27-S72.

122 Fine MJ, Auble TE, Yealy DM, et al. A prediction rule to identify low-risk patients with community-acquired pneumonia. $N$ Engl J Med 1997; 336: 243-250.

123 Houck PM, Bratzler DW, Nsa W, et al. Timing of antibiotic administration and outcomes for Medicare patients hospitalized with community-acquired pneumonia. Arch Intern Med 2004 164: 637-644.

124 Meehan TP, Fine MJ, Krumholz HM, et al. Quality of care, process, and outcomes in elderly patients with pneumonia. JAMA 1997; 278: 2080-2084. 
125 Siempos II, Vardakas KZ, Kopterides P, et al. Adjunctive therapies for community acquired pneumonia: a systematic review. J Antimicrob Chemother 2008; 62: 661-668.

126 Wunderink RG, Rello J, Cammarata SK, et al. Linezolid vs vancomycin: analysis of two double-blind studies of patients with methicillin-resistant Staphylococcus aureus nosocomial pneumonia. Chest 2003; 124: 1789-1797.

127 Falagas ME, Siempos II, Vardakas KZ. Linezolid versus a glycopeptide or $\beta$-lactam for the treatment of Gram-positive bacterial infections: a meta-analysis of randomized controlled trials. Lancet Infectious Diseases 2008; 8: 53-66.

128 Bernardo K, Pakulat N, Fleer S, et al. Subinhibitory concentrations of linezolid reduce Staphylococcus aureus virulence factor expression. Antimicrob Agents Chemother 2004; 48: 546-555.

129 Labandeira-Rey M, Couzon F, Boisset S, et al. Staphylococcus aureus Panton-Valentine leukocidin causes necrotizing pneumonia. Science 2007; 315: 1130-1133. 